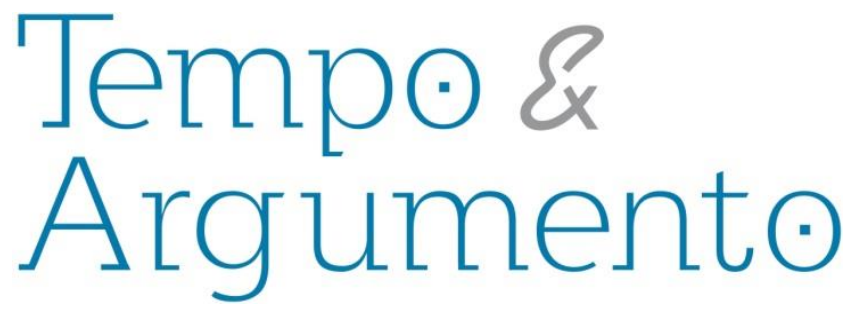

\title{
Narrativas nacionais e competência histórica na formação inicial de professores primários espanhóis ${ }^{1}$
}

\begin{abstract}
Resumo
Neste trabalho, foram analisadas as competências de pensamento histórico e a presença de características de narrativa nacional entre 283 estudantes espanhóis do Grau de Licenciatura em Ensino Primário de Murcia e de Valência. Examinaram-se os seus relatos históricos sobre a expansão cristã na Península Ibérica em território muçulmano durante a Idade Média. Utilizaram-se métodos qualitativos para identificar os níveis de complexidade da exposição a partir de conhecimentos substantivos e conceitos metodológicos, e uma avaliação quantitativa para relacionar esses níveis de complexidade com os níveis cognitivos e narrativos, através da taxonomia SOLO. Também se avaliou em que medida se representam elementos discursivos próprios de uma narrativa nacional. Os resultados confirmam uma educação histórica deficiente dos futuros professores primários, tanto em conceitos históricos de segunda ordem quanto na reprodução de uma narrativa nacional já caduca pela historiografia. Também se confirmou que a presença e complexidade do pensamento histórico nas narrativas é maior quanto maior é o nível e pertinência dos conteúdos históricos substantivos.
\end{abstract}

Palavras-chave: Pensamento Histórico. Narrativa Nacional. Formação Inicial do Professor. Educação Histórica.

\author{
Jorge Sáiz Serrano \\ Doutor em Geografia e História pela \\ Universidade de Valencia. Professor associado \\ na mesma Universidade. \\ Valencia - Espanha \\ jsaizser@gmail.com \\ Cosme Jesús Gómez Carrasco \\ Doutor em Historia pela Universidade de \\ Castilla - La Mancha. Profesor da \\ Universidade de Murcia. \\ Murcia - Espanha \\ cjgomez@um.es \\ Ramón López Facal \\ Doutor em Historia pela Universidade de \\ Santiago de Compostela. Professor na \\ mesma Universidade. \\ Santiago de Compostela - Espanha \\ ramon.facal@usc.es
}

\section{Para citar este artigo:}

SÁIZ SERRANO, Jorge; GÓMEZ CARRASCO, Cosme Jesús; LÓPEZ FACAL, Ramón. Narrativas nacionais e competência histórica na formação inicial de professores primários espanhóis. Tempo e Argumento, Florianópolis, v. 9, n. 22, p. 174 - 197, set./dez. 2017.

\author{
DOI: $10.5965 / 2175180309222017174$ \\ http://dx.doi.org/10.5965/2175180309222017174
}

\footnotetext{
${ }^{1}$ Este trabalho contou com financiamento dos projetos de investigação coordenados EDU2012-37909-C0301 e EDU2012-37909-C03-03 do Plano Nacional de I+D+i (MINECO, do Governo de Espanha), de fundos FEDER da UE e das redes de excelência: Red14 e NEDAT.
} 


\title{
National Narratives and Historical Competencies in Spanish Initial Teacher Training
}

\begin{abstract}
This paper analyzes historical thinking skills and the presence of elements of a national narrative among 283 students at Grade of Primary Education in Murcia and Valencia, future primary teachers in Spain. It's analyzed their narratives about Christian expansion into Muslim territory in Medieval Iberian Peninsula: it's an historical content linked to the Spanish national narrative. Qualitative methods are used to determine levels of narrative complexity in substantive contents and in methodological knowledge or second order concepts. It's also used a quantitative assessment of levels of complexity and its relation to cognitive levels of written using the SOLO taxonomy. It's also assessed the presence of discursive elements of a national narrative. The results confirm a poor historical education of future teachers of Primary Education in second order concepts and in the reproduction of national narratives. It is also confirmed that the presence and complexity of historical thinking in narratives is higher the higher the level and relevance of substantive historical content.
\end{abstract}

Keywords: Historical Thinking; National Narratives; Initial Teacher Training; History Education.

\section{Introdução}

As narrativas históricas são uma importante fonte de informação para investigar o conhecimento histórico e a capacidade de lhe dar significado, tal como o demonstram numerosos estudos, tais como os de Barca (2015), Henríquez e Ruíz (2014), Kropman, Van Boxtel e Van Drie (2015), Lévesque, Croteau e Gani (2015), Sáiz e López Facal (2015 e 2016) 
e Sant, González, Santiesteban, Pagès e Oller (2015). Os relatos históricos dão uma imagem dos níveis de compreensão e aprendizagem dos sujeitos investigados: contribuem com um retrato substantivo do passado e informam sobre o conhecimento e o uso das competências do conhecimento histórico. Este estudo assume ambas as perspectivas para analisar relatos de professores primários em formação sobre a expansão cristã na Península Ibérica durante a Idade Média com prejuízo para os muçulmanos. Examinaram-se textos de 283 estudantes do Grau de Licenciatura em Ensino Primário de duas universidades espanholas (Valência e Murcia), aplicando uma perspetiva quantitativa e qualitativa. O objetivo é duplo: em primeiro lugar, o de estudar a organização discursiva dos trabalhos escritos destes futuros professores primários para conhecer os seus níveis de competência histórica como aptidão metodológica própria da disciplina de História (DOMíNGUEZ, 2015). Em segundo lugar, o de analisar o conteúdo dos referidos relatos sobre o período medieval peninsular para comprovar o grau de mediação do que se considera como narrativa nacional espanhola, com a presença de estereótipos e marcos do relato da "Reconquista" cristã sobre os muçulmanos e o uso de marcadores discursivos de identificação nacional (SÁlZ, 2015).

Este trabalho inscreve-se no paradigma de didática da história conhecido como pensamento histórico (historical thinking), assumido no Canadá e nos Estados Unidos por autores como Clark (2011), Lévesque (2008), Seixas (2011), VanSledright (2011 e 2014) e Wineburg (2001), embora a sua origem se situe na inovação e investigação em didática da história a partir dos anos 70-80 no Reino Unido (LEE, 2005). A perspectiva do pensamento histórico foi sintetizada na Espanha por Domínguez (2015), Gómez e Miralles (2015), Gómez, Ortuño e Molina (2014) Sáiz (2015) e Sáiz e López Facal (2015). De acordo com este modelo, há dois tipos de conteúdos históricos. Por um lado, os conteúdos substantivos ou de primeira ordem, conteúdos de história, ou seja, o que sabemos do passado sob a forma de dados, datas, personagens, conceitos e fatos. Por outro lado, os conteúdos estratégicos de segunda ordem, ou conceitos metodológicos, conteúdos sobre história, quer dizer, como se representa o passado e que significado lhe atribuímos; são aptidões relacionadas com as competências do historiador que consideramos competências históricas. Um dos instrumentos para as investigar, bem como para as 
ensinar, é recorrer às narrativas históricas. Este estudo analisa, nos 283 relatos, quatro categorias das referidas competências históricas conforme a proposta realizada por Seixas e Morton (2013) e incorporando outras (LÉVESQUE, 2008; VANSLEDRIGHT, 2014; DOMÍNGUEZ, 2015). Em primeiro lugar, a competência de relevância histórica entendida como o grau de transcendência e valor que se concede ao fenômeno relatado na sua ligação com outros. Em segundo lugar, a de causalidade, como a aptidão para expor o fenômeno integrando as múltiplas causas que o explicam. Em terceiro lugar, a de tempo histórico, como a aptidão para descrever as alterações do fenômeno usando o tempo de forma flexível. E, finalmente, a categoria de dimensão ética ou consciência histórica, como a faculdade para valorizar o fenômeno relacionando-o tanto com o seu contexto quanto com o presente. Como complemento analítico para a organização das narrativas, também recorremos à taxonomia elaborada por J. Biggs e C. Tang (2007) conhecida por SOLO (Structure of the Learning Outcome), uma ferramenta criada para o ensino superior que categoriza os níveis de complexidade do pensamento aplicado a trabalhos escritos relativamente a um tema, partindo de níveis básicos ou de reconhecimento, até níveis de abstração profunda.

O estudo de relatos históricos também permite que nos aproximemos ao grau de mediação cultural de esquemas narrativos preexistentes. De fato, a partir da psicologia social podemos compreender as representações sociais do passado mediante a noção de “ação mediada" (WERSTCH, 2002): esta perspectiva baseia-se em que as referidas representações decorrem do consumo e uso que as pessoas façam de narrativas já existentes, entendidas como ferramentas culturais a modo de teoria implícitas. Werstch (2002 e 2004) distingue dois grandes tipos de narrativas: por um lado, os esquemas narrativos mestres ou narrativas mestras que operam como modelos construídos num contexto social e partilhados no seio de um coletivo que condicionam as representações sociais do passado; por outro lado, as narrativas específicas, entendidas como discursos, usos ou consumos dessas narrativas mestras geradas pelas pessoas ou pelos coletivos, podendo ser de natureza muito diversa. Este modelo teórico pode, de certa forma, aplicar-se às narrativas nacionais e aos diferentes discursos, usos e representações do passado gerados por pessoas e grupos. As narrativas nacionais, bem como a história 
oficial difundida por um Estado-nação, funcionam como narrativas mestras que medeiam ou condicionam as representações sociais sob a forma de narrativas específicas (com as suas personagens, eventos, etc.) criadas por indivíduos e por grupos.

Essa mediação verifica-se tanto no conteúdo quanto na forma. Na forma, segundo o sujeito narrativo atue e a primeira pessoa do plural seja utilizada revelando diferentes formas de identificação, tais como gênero ou grupo, sendo uma delas, a nacional (BARTON e LEVSTIK, 2004; PLÁ, 2005). Para este estudo, é importante observar o grau e a forma em que se usa a primeira pessoa do plural; quer o pronome "nós" quer o possessivo "nosso", bem como o recurso essencial a referências explícitas à Espanha ou aos espanhóis na Idade Média. Isto constitui uma característica específica das narrativas nacionais (CARRETERO e BERMÚDEZ, 2012; LÓPEZ, CARRETERO e RODRÍGUEZ-MONEO, 2015).

No que diz respeito ao conteúdo, a mediação narrativa também se constata na presença de fatos, personagens e termos próprios de uma narrativa nacional espanhola do período medieval. Consideramos aqui a existência de uma narrativa nacional sobre a história da Espanha, construída ao longo do século XIX, durante a consolidação do Estado-nação e do nacionalismo espanhol, embora difundida em grande escala ao longo do século XX. Um relato com conteúdos essencialistas que remontaria à unidade da “Espanha” (com fronteiras estáveis ou com uma unidade territorial) ou à origem de um coletivo de "espanhóis" a períodos pré-contemporâneos (LÓPEZ FACAL e SÁlZ, 2016). Entre eles, têm peso os do período medieval, pois consideram a expansão cristã em território muçulmano como um processo de gestação da Espanha, processo para o qual, no final do século XIX, se construiu o conceito de "Reconquista", uma criação historiográfica que conferiu valor patriótico a um vocábulo já existente (RÍOS, 2011). Desde então, integrou-se no relato fundacional da identidade espanhola a expansão cristã como “Reconquista". Paralelamente, considera-se o território e o período muçulmano, o Al-Andalus, a partir de um plano secundário e como uma alteridade, mais em termos culturais, como fase de convivência multicultural e/ou de esplendor cultural. Atualmente, os manuais escolares de história privilegiam o conhecimento declarativo da mudança política, como uma sucessão de etapas e espaços de Al-Andalus aos reinos 
cristãos e utilizam o termo "Reconquista", um conceito que conserva o seu conteúdo identitário (SÁIZ, 2015). Na atual historiografia medieval também perdura o referido termo já que se defende a sua utilidade para caracterizar o fenômeno e período de expansão cristã medieval sobre o Islão peninsular: embora se reconheça a sua natureza de justificação ideológica a posteriori, não se criou uma denominação alternativa.

\section{Método}

\section{Objetivos}

Pretendeu-se identificar nos relatos de futuros docentes do Ensino Primário os níveis de competência histórica e o grau de mediação da narrativa nacional espanhola. Esta finalidade foi abordada com quatro objetivos:

Comprovar o uso de conceitos históricos metodológicos nos seus relatos, que indicam como organizam historicamente os conteúdos.

Classificar a complexidade e a coerência do seu discurso com a taxonomia SOLO.

Determinar quais conteúdos substantivos apresentam os relatos sobre a conquista cristã do território muçulmano e, dentro destes, a presença de estereótipos próprios da narrativa nacional espanhola.

Reconhecer marcadores discursivos de identificação nacional; quer o uso da primeira pessoa do plural, quer a referência à Espanha ou aos espanhóis no período relatado.

\section{População e amostra}

Participaram da pesquisa estudantes do Grau de Licenciatura em Ensino Primário que frequentavam a última disciplina obrigatória da área de Didática das Ciências Sociais nas Universidades de Valência e Murcia, no ano letivo 2014/2015. Tratou-se de uma amostra probabilística: todos os grupos que frequentaram as disciplinas tiveram as mesmas possibilidades de ser escolhidos. Realizou-se uma amostragem não 
Tabela 1.

Número de estudantes que participaram na investigação por universidade

\begin{tabular}{|c|c|c|}
\hline & Frequência & Percentagem \\
\hline Universidade de Murcia & 151 & 53,4 \\
\hline Universidade de Valência & 132 & 46,6 \\
\hline Total & 283 & 100 \\
\hline
\end{tabular}

\section{Instrumento}

Os universitários redigiram um texto de síntese do processo de conquista cristã do território muçulmano na Península Ibérica medieval, na aula da disciplina de Didática das Ciências Sociais e no início do ano letivo (setembro-outubro de 2013). Para minimizar as interferências, não se deu qualquer indicação de extensão, conteúdo ou forma. Apenas Ihes foi dito que imaginassem como destinatário outro docente estrangeiro em formação que desconhecesse o tema por completo. Os relatos deste tipo são um instrumento habitual para avaliar conceitos metodológicos históricos e analisar a representação social do passado e a sua relação com a memória coletiva. O conteúdo pedido, a expansão cristã medieval na península ibérica muçulmana, leciona-se no ensino básico (Primário e Secundário) e no Pré-Universitário, e está presente nos âmbitos de socialização quotidiana, quer no folclore e tradições populares - festas de "mouros e cristãos " - quer nos meios de comunicação de massas através de séries de inspiração histórica (tal como a recente "Isabel”).

A validade do instrumento de recolha de informação (um texto de síntese histórica) para os objetivos propostos, fundamentou-se em estudos como os de Bage (1999), Barton e Levstik (2004), Cooper (2014), Carretero e Bermúdez (2012), Carretero e Van Alphen (2014), López, Carretero e Rodríguez-Moneo (2015), Henríquez e Ruiz (2014), Monte-Sano (2010) e VanSledright (2008). O instrumento foi validado por peritos em 
Didática das Ciências Sociais de três universidades espanholas, seguindo alguns dos passos propostos por Alfageme, Miralles e Monteagudo (2010). ${ }^{2}$

Estabeleceram-se diferentes categorias de informação, por sua vez divididas em níveis. A análise empírica piloto permitiu codificar quatro níveis de complexidade de marcadores de competências históricas. O nível o ou nulo, como ausência destas, correspondente a pouca informação substantiva e/ou a erros históricos notórios. O nível 1 ou básico, para os relatos que descrevem uma informação histórica mínima, apresentada linearmente, ou que contribuem com pelo menos um marcador de competências de pensamento histórico, embora com um nível baixo. O nível 2 ou médio, para trabalhos escritos com, pelo menos, dois marcadores de competências históricas, um deles de nível médio e outro de nível médio ou baixo. Finalmente, estabeleceu-se o nível 3 para trabalhos escritos com níveis de pensamento histórico alto por integrarem na sua explicação um ou mais marcadores de nível consolidado.

Quanto aos conteúdos substantivos, fixaram-se outros quatro níveis. O nível o corresponde a relatos com vazios históricos notórios ou erros de informação graves, quer por não apresentarem dados, quer por apresentarem dados não pertinentes. O nível 1 atribuiu-se aos trabalhos escritos com mera informação descritiva com um ordenamento linear: contribuem com alguns marcos ordenados de forma correta. Trata-se de fatos político-territoriais, desde a invasão muçulmana da Península Ibérica, em 711, até a conquista cristã do reino de Granada em 1492. O nível 2 pertence a trabalhos escritos que combinam esse mesmo relato básico de acontecimentos políticos com fenômenos socioeconômicos, culturais e inclusivamente com avaliações sobre a herança muçulmana ou desse período. O nível 3 corresponde aos relatos de maior riqueza informativa que integram adequadamente explicações de conteúdo político com explicações socioeconômicas e culturais.

\footnotetext{
${ }^{2}$ Utilizou-se um questionário para classificar de 1 a 4 a validade das categorias de análise e a adequação aos níveis de complexidade estabelecidos. Todos os itens receberam uma pontuação média que ultrapassou os 3 pontos. Também se pediu uma avaliação qualitativa do instrumento, que aplicasse as recomendações recebidas na fase de análise de resultados. A informação qualitativa recolheu-se e apresentou-se na base de dados Filemaker Pro, o que permitiu melhorar a formulação das categorias e os seus limites. A informação quantitativa foi posteriormente codificada no pacote estatístico SPSS v.17.0.
} 
Também se codificou a denominação sobre o conteúdo do relato, mais concretamente, se foi utilizada ou não a categoria historiográfica "Reconquista" ou se foram utilizadas outras (conquista, expansão, expulsão). Finalmente, a análise foi completada com o estudo do nível de complexidade das narrativas conforme a taxonomia SOLO (BIGGS; TANGS, 2007), utilizando as categorias deste modelo: préestrutural (nível o), uni-estrutural (nível 1), multi-estrutural (nível 2), relacional e abstrato alargado (nível 3).

\section{Métodos e técnicas de análise}

Adotou-se um desenho metodológico próprio dos métodos não experimentais baseados na busca empírica e sistemática de um fenômeno cujas variáveis independentes já ocorreram ou não são manipuláveis (KERLINGER, 2002). Pretende-se conhecer uma realidade para depois obter modelos explicativos sobre as características do discurso histórico dos futuros professores do Ensino Primário comparando os dados obtidos em duas universidades. A análise dos dados combina uma perspetiva quantitativa e qualitativa. Diferentes investigações sobre a educação histórica incidem na complementaridade de ambas as perspectivas (ASHBY, 2004; BARCA, 2005; BARTON, 2012). A investigação foi iniciada a partir de uma concepção transversal exploratória, através de um grupo piloto (15\% dos dados recolhidos), passando-se depois para uma concepção transversal descritiva.

As técnicas de análise quantitativa foram aplicadas com a codificação das categorias que o permitiram através do pacote estatístico SPSS: análise de frequências, médias, percentagens, qui-quadrado, tabelas de contingência e análise da dependência entre as variáveis. O objetivo desta análise foi descobrir a estrutura subjacente aos relatos dos sujeitos e verificar correlações entre as categorias consideradas.

O tratamento de dados qualitativos analisa a complexidade discursiva e conceitual das narrativas. A análise qualitativa permitiu dar sentido à informação textual. A validade da investigação qualitativa depende da representatividade dos dados, da fundamentação teórica e da sua análise e interpretação (ANGUERA, 1998). Usou-se uma codificação aberta na análise discursiva para determinar os níveis do seu conteúdo e das categorias 
consideradas de competências de pensamento histórico, seguindo estratégias próprias da grounded theory ou teoria fundamentada (CORBIN; STRAUSS, 2008), utilizadas também noutras investigações de Educação Histórica (BARCA; SCHMIDT, 2013).

\section{Hipóteses}

Formularam-se quatro hipóteses sobre as características previsíveis nos relatos quanto à sua forma (complexidade discursiva segundo a taxonomia SOLO e segundo níveis de pensamento histórico), conteúdo (conhecimentos históricos) e presença de elementos de narrativa nacional espanhola.

1. Relativamente ao nível de complexidade discursiva dos relatos conforme a taxonomia SOLO, e dado o nível educativo superior dos sujeitos analisados (no final da sua licenciatura universitária), previa-se que o grosso dos trabalhos escritos alcançasse níveis elevados dessa taxonomia.

2. Quanto ao conhecimento e uso de conceitos metodológicos de pensamento histórico, e dada a sua formação como futuros professores primários generalistas, com poucos conteúdos disciplinares de história, previam-se níveis variáveis, com alguma presença de níveis médios. Contudo, não se excluía um maior nível de aprendizagem histórica procedimental, dada a presença da história como disciplina do segundo ano do ensino pré-universitário que exige trabalho de competências de explicação e com fontes.

3. Quanto ao nível de conteúdos históricos substantivos presente nos trabalhos escritos, considerou-se possível encontrar conhecimentos básicos, em alguns casos nulos, dada a presença desse conteúdo (passado medieval peninsular) tanto no conhecimento informal (meios de comunicação, festas) como no ensino formal anterior (ensino secundário pós-obrigatório).

4. No que diz respeito à presença de características de narrativa nacional espanhola, quer a mediação do relato de Reconquista, quer o uso da primeira pessoa do plural ou a identificação com os espanhóis ou com Espanha no passado medieval, era previsível a sua presença em boa parte dos trabalhos escritos e, sobretudo, do termo Reconquista, largamente difundido no curriculum e nos manuais escolares. 
Resultados

Nas seguintes tabelas apresentam-se os dados obtidos a partir da análise quantitativa do nível dos conteúdos históricos (tabela 2), a presença e níveis de uso de competências históricas como conceitos metodológicos (tabela 3) e os níveis da taxonomia SOLO (tabela 4).

Tabela 2.

Nível de conteúdos históricos nas narrativas

\begin{tabular}{|c|c|c|}
\hline & Frequência & Percentagem \\
\hline Nulo (0) & 142 & 50,2 \\
\hline Básico (1) & 107 & 37,8 \\
\hline Médio (2) & 33 & 11,7 \\
\hline Alto (3) & 1 & 0,4 \\
\hline Total & 283 & 100 \\
\hline
\end{tabular}

Tabela 3.

Presença e níveis de meta-conceitos de pensamento histórico nas narrativas

\begin{tabular}{|c|c|c|}
\hline & Frequência & Percentagem \\
\hline Nulo (0) & 139 & 49,1 \\
\hline Básico (1) & 119 & 42,0 \\
\hline Médio (2) & 24 & 8,5 \\
\hline Alto (3) & 1 & 0,4 \\
\hline Total & 283 & 100 \\
\hline
\end{tabular}

Tabela 4.

Tipologia SOLO nas narrativas

\begin{tabular}{|c|c|c|}
\hline & Frequência & Percentagem \\
\hline Pré-estrutural & 131 & 46,3 \\
\hline Uni-estrutural & 120 & 42,4 \\
\hline Multi-estrutural & 31 & 11,0 \\
\hline Relacional & 1 & 0,4 \\
\hline Total & 283 & 100 \\
\hline
\end{tabular}


Os resultados confirmam um baixo nível de educação histórica dos estudantes de Licenciatura de Magistério do Ensino Primário em ambas as universidades. Em primeiro lugar, pela falta de conteúdos substantivos, o que sabem sobre o conteúdo histórico específico, apesar deste se encontrar presente na sua formação básica e conhecimento informal. Em segundo lugar, pela falta de competências para organizar historicamente um relato, o como narram esse conteúdo. Metade dos estudantes não fornece informações de destaque e, a mesma percentagem, também não revela capacidades ou competências históricas expositivas mínimas. Se aplicarmos a taxonomia SOLO, 46\% dos sujeitos não soube articular o relato de forma aceitável. A característica mais destacável das referidas narrativas é a sua incoerência. A uma grande parte dos trabalhos escritos faltam as condições mínimas exigíveis a jovens universitários em formação como docentes do Ensino Primário. Dois exemplos aproximam-nos do paupérrimo nível dos trabalhos:

No ano 711 os cristãos começaram a conquista do território muçulmano através de Gibraltar e estabeleceram o seu reinado por toda a Península Ibérica em reinos dirigidos pelos califas, constituindo-se assim os diferentes califados. Estabeleceram a capital em Toledo. Os reinos cristãos terminaram a sua conquista em Granada, ficando com a totalidade dos territórios. (Ref. 135 UMU)

Por Espanha ser uma península, a primeira parte da colonização romana foi no norte de Espanha, pois esta está diretamente ligada ao império romano. Após inúmeros anos de guerra, o império romano foi conquistando em sentido descendente, de norte para sul. Impondo as leis de Roma, a cultura, a língua, a religião e as suas infraestruturas e reduzindo pouco a pouco a colonização muçulmana. Os árabes viram-se obrigados a retroceder até África, pois entre os dois continentes é relativamente estreito. (Ref. $35 \mathrm{UV}$ )

Estes erros e deficiências são o resultado de recordações desconexas que resultam em representações que misturam etapas e períodos (período romano e período muçulmano, invasão “cristã" pelo norte ou pelo sul), que se podem dever a que a sua informação histórica apenas proceda da lembrança de itens ou capítulos de conteúdos históricos do próprio currículo do Ensino Primário.

Em contraste com este primeiro grupo, encontramos cerca de $40 \%$ de relatos que cumpriram os níveis de exposição mínimos exigidos a universitários. São narrativas lineares e descritivas de fatos históricos, embora de forma unidimensional. 
Contextualizam um início e um final do processo, da invasão muçulmana (711) até à conquista de Granada, (1492) e indicam algumas personagens e marcos. No entanto, carecem de domínio de competências históricas e os fenômenos assinalados limitam-se a ordenar fatos de natureza político-territorial, por vezes de forma fragmentária e com descontinuidades no tempo. É significativo que estes relatos descritivos políticoterritoriais tenham mais presença entre os estudantes de Murcia, provavelmente devido à sua memória, já que este tema estava incluído no exame de acesso à universidade de história da região murciana. Os fatos e personagens mais mencionados são representativos da narrativa nacional: Pelayo, a Batalha de Covadonga; Cid; Jaime I (no caso valenciano), os Reis Católicos e a tomada de Granada em 1492. O seguinte fragmento ilustra este perfil dos trabalhos escritos:

Os muçulmanos conquistaram a Península Ibérica ao longo do século VIII. Essa conquista teve como consequência o desaparecimento do reino dos visigodos. Os muçulmanos conquistaram quase toda a Península exceto a faixa norte. A partir daí, formaram-se núcleos de resistência que, com o tempo, chegaram a toda a Península. Houve duas grandes coroas, Aragão e Castela. Foi um processo lento. Os Reis Católicos foram os que definitivamente acabaram a Reconquista em 1492 com a tomada de Granada. (Ref. 1 UMU)

Se atendermos aos níveis mais altos alcançados pelas narrativas, 12\% têm um nível de conteúdos substantivos médio (tabela 2), enquanto que $9 \%$ mostram o domínio de um ou vários conceitos metodológicos de forma consistente, quer dizer, um nível médio e alto (tabela 3). Além disso, uma grande parte destes relatos contêm informações substantivas mais estruturadas e consistentes, e coincidem com as narrativas classificadas como multi-estruturais segundo a taxonomia SOLO (tabela 4). Nestes trabalhos escritos constam mais personagens e marcos significativos (mencionam o Califado de Córdoba, Abderramão III, o reino de Navarra, Sancho III, os almóadas e almorávidas, os reinos de Taifas e até fases do processo de expansão cristã).

Ao analisar cada uma das categorias de competências históricas ou conceitos metodológicos, vemos que sete de cada dez narrativas não contêm no seu discurso qualquer marcador sobre a importância do processo histórico nem sequer a um nível baixo. Na sua maioria, narram o processo histórico de forma desconexa com a atual 
realidade social, econômica e territorial. A referência à importância do processo mais repetida é a consideração da herança cultural e artística muçulmana (monumentos e mesquitas):

Durante sete séculos, nos quais a convivência foi passando por melhores e piores fases em diferentes zonas da península, então chamada AlAndalus, e de forma desigual, os árabes estabeleceram aqui a sua cultura e foram deixando grandes contributos culturais tanto na nossa língua e nas nossas tradições e costumes (sistemas de regadio, influências culinárias) quanto na herança arquitetónica e artística (arte moçárabe, arte mudéjar). (Ref. 44 UV)

O facto da população muçulmana ter permanecido tantos séculos na Península lbérica fez com que muitos dos nossos costumes, tradições e identidade como povo tenham numerosas raízes muçulmanas. (Ref. 20 UV)

Exceto em dois casos, é muito reveladora a ausência da competência histórica de causalidade, o uso de causas e consequências. Não se fazem alusões aos motivos que provocaram a fácil conquista muçulmana, o avanço dos reinos cristãos sobre território muçulmano e aos diferentes ritmos deste processo no tempo. Também não se expõem argumentos sobre a temporalidade, as mudanças e permanências associadas ao processo histórico proposto, nem o uso da consciência histórica, em que, através de juízos de valor se relacionem esses fatos históricos com a atual configuração social, econômica, política e cultural.

O cruzamento de variáveis através das tabelas de contingência no pacote estatístico SPSS v.17.0 mostra resultados significativos. Em primeiro lugar destacam que a complexidade dos relatos e a presença de marcadores de pensamento histórico aumentam paralelamente com o aumento de conteúdos substantivos: os estudantes que oferecem uma maior quantidade de informação histórica fazem-no com mais qualidade organizativa, quer na gradação estabelecida segundo o seu pensamento histórico (nível básico e médio), quer na taxonomia SOLO (nível multi-estrutural). Isto demonstra uma correspondência íntima entre ambas as variáveis e a necessidade de um ensino que combine conteúdos históricos com competências de pensamento histórico, contemplando sempre as interrelações entre ambos os aspectos (LEE, 2005; DOMíNGUEZ, 2015). 
A correspondência entre a complexidade do pensamento histórico e a pertinência e quantidade dos conteúdos históricos constata-se nas tabelas seguintes (tabelas 5, 6 e 7). Nelas, realizou-se uma tabela de contingência, o teste do qui-quadrado de Pearson e o teste Tau-b de Kendall, para verificar a hipótese de independência entre as variáveis e o grau de dependência entre as mesmas. O valor do qui-quadrado (617,130, com uma significação assimptótica bilateral de 0,000), implica que as variáveis de conteúdos históricos e complexidade de pensamento histórico são dependentes (tabela 7). A dependência entre as variáveis, segundo o teste de Tau-b de Kendall, alcança um valor de 0,906 (tabela 8), pelo que se pode afirmar que há uma grande dependência entre ambas as variáveis.

Tabela 5.

Relações de contingência nas variáveis "conteúdos históricos" e "complexidade do pensamento histórico"

\begin{tabular}{|c|c|c|c|c|c|}
\hline & $\begin{array}{c}\text { Pré-estrutural com } \\
\text { falhas históricas }\end{array}$ & $\begin{array}{c}\text { Estrutural } \\
\text { linear básica }\end{array}$ & $\begin{array}{c}\text { Pensamento } \\
\text { histórico } \\
\text { médio }\end{array}$ & $\begin{array}{c}\text { Pensamento } \\
\text { histórico alto }\end{array}$ & TOTAL \\
\hline Nulo & 139 & 2 & 1 & 0 & 142 \\
\hline Básico & 0 & 100 & 7 & 0 & 107 \\
\hline Médio & 0 & 17 & 16 & 0 & 33 \\
\hline Alto & 0 & 0 & 0 & 1 & 1 \\
\hline Total & 139 & 119 & 24 & 1 & 283 \\
\hline
\end{tabular}

Tabela 6.

Testes de qui-quadrado das variáveis "conteúdos históricos" e "complexidade do pensamento histórico"

\begin{tabular}{|c|c|c|c|}
\hline & Valor & Gl & Seg. assimptótica (bilateral) \\
\hline Qui-quadrado de Pearson & 617,130 & 9 & 0,000 \\
\hline Razão de verosimilhanças & 403,237 & 9 & 0,000 \\
\hline Associação linear por linear & 221,924 & 1 & 0,000 \\
\hline N de casos válidos & 283 & & \\
\hline
\end{tabular}


Tabela 7.

Medidas simétricas das variáveis "conteúdos históricos" e "complexidade do pensamento histórico"

\begin{tabular}{|c|c|c|c|c|c|}
\hline & Valor & Erro típ. assint. & $\begin{array}{c}\text { T } \\
\text { aproximadab }^{b}\end{array}$ & $\begin{array}{c}\text { Seg. } \\
\text { Aproximado }\end{array}$ \\
\hline $\begin{array}{c}\text { Ordinal por } \\
\text { ordinal }\end{array}$ & Tau-b de Kendall & 0,906 & 0,020 & 40,051 & 0,000 \\
\hline & $\begin{array}{c}\text { N de casos } \\
\text { válidos }\end{array}$ & 283 & & & \\
\hline
\end{tabular}

a. Assumindo a hipótese alternativa;

b. Utilizando o erro típico assimptótico baseado na hipótese nula.

Finalmente, examinemos a presença de marcadores discursivos próprios de narrativas nacionais, no nosso caso do relato nacional espanhol. Neste âmbito, o primeiro marcador a analisar seria a utilização do conceito "Reconquista" face a outras denominações do processo (Tabela 8).

Tabela 8.

Denominação do processo

\begin{tabular}{|c|c|c|c|}
\hline & Frequência & Percentagem & Percentagem válida \\
\hline Reconquista & 182 & 64,3 & 64,3 \\
\hline Conquista & 58 & 20,5 & 20,5 \\
\hline Expulsão & 14 & 4,9 & 4,9 \\
\hline Convivência & 6 & 2,1 & 2,1 \\
\hline Nulo & 23 & 8,1 & 8,1 \\
\hline Total & 283 & 100,0 & 100,0 \\
\hline
\end{tabular}

Cerca de $65 \%$ dos estudantes utilizaram o termo "Reconquista". Esta elevada percentagem explica-se pela utilização deste conceito pela história acadêmica e escolar no currículo e nos manuais do ensino secundário. Mas também pela sua vasta difusão em recentes produtos culturais de massas, tais como séries de televisão (Isabel). Não é uma surpresa que esta perdure no imaginário dos universitários como se previa, tal como também se constatou noutros trabalhos (LÓPEZ; CARRETERO;RODRÍGUEZ-MONEO, 2015). 
A análise de outros marcadores nas narrativas valencianas proporciona dados complementares como a tipologia do sujeito narrativo dos trabalhos escritos. Embora predomine o recurso a um narrador implícito, em $25 \%$ dos relatos consta a primeira pessoa do plural. São referências de pertença a um espaço próprio (o nosso país, território, as nossas terras, a nossa península) ou expressões de identificação com pessoas e a sua cultura passada e o seu impacto no presente, especialmente com os cristãos ou com a influência dos "outros", os muçulmanos, na "nossa" cultura, história, identidade, costumes e civilização identificada como a cristã do passado. Por outro lado, o aparecimento do termo Espanha ou espanhóis, do povo espanhol como vínculo do presente e do passado medieval, foi um marcador encontrado em $23 \%$ dos relatos. Além disso, combina-se com um protagonismo dos Reis Católicos no processo, embora também se destaque a figura de Jaime I:

Em suma, o que finalmente criou a Espanha que atualmente conhecemos foi a união da rainha Isabel de Castela com Fernando de Aragão, que tornou possível a união dos territórios e a conquista final da península ibérica por parte dos cristãos. (Ref. 75 UV)

Para assegurar a unidade nacional do país, os Reis Católicos utilizaram a religião católica como característica própria de todos os cidadãos espanhóis. (Ref. 82 UV)

A Reconquista foi um longo processo que durou quase seis séculos e no qual, pouco a pouco, as tropas espanholas foram avançando do norte para baixo, conquistando os territórios e expulsando os muçulmanos (...). Lideradas por Jaime I no ano 1238, as tropas espanholas chegaram a Valência e no dia 9 de outubro conquistaram o território valenciano. (Ref. 128 UV)

Os cristãos começaram a reconquistar os territórios de norte a sul da península e fizemos com que os muçulmanos se fossem retirando (...). Com a chegada dos Reis Católicos assistimos à unificação territorial e ao reforço da Coroa e então os Reis Católicos em 1492 acabaram a Reconquista de Espanha. (Ref. 124, UV)

No ano de 722 deu-se a conquista da Península ibérica por parte dos muçulmanos. Os cristãos começaram a conviver com os muçulmanos até ao casamento e daí a união dos reinos de Aragão e Castela (por parte de Fernando e Isabel) que unificaram Espanha. (Ref. 107, UV)

Constatam-se marcadores discursivos de ligação com uma comunidade imaginada nacional permanente ou formada no passado medieval, uma das características mais específicas das narrativas nacionais. É de particular interesse saber qual é a complexidade 
cognitiva e a presença de marcadores de pensamento histórico entre estes relatos nacionais. Constata-se que $89 \%$ dos trabalhos escritos são, quer de nível nulo (19), quer de nível básico (descritivo e linear). Estes dados permitem enunciar uma nova hipótese: uma educação histórica mais completa, tanto em conteúdos quanto em competências de pensamento histórico, pode reduzir a presença de estereótipos próprios das narrativas nacionais. Seria conveniente alargar esta ligação, já constatada noutras investigações (LÓPEZ, 2012; SÁIZ e LÓPEZ FACAL, 2016; SÁIZ, 2015), a futuros estudos: em que medida um conhecimento histórico disciplinar mais sólido durante a formação inicial de professores de história e de professores primários, que inclua conteúdos substantivos e competências históricas, consegue reduzir as representações próprias das narrativas nacionais. Consideramos que a referida educação histórica poderia mitigar, embora não impedir, o impacto desta narrativa nacional, ao dotar os futuros docentes de ferramentas intelectuais para compreenderem e darem significado ao passado evitando identificações românticas e essencialistas.

\section{Discussão e conclusões}

Da análise dos resultados concluímos não ser possível verificar as hipóteses avançadas, especialmente no perfil comum de relatos de futuros professores primários: trabalhos escritos de complexidade organizativa multi-estrutural, com marcadores de competências de pensamento histórico (nível básico e médio) e que proporcionem conteúdos históricos básicos ou médios. Os resultados mostram que os futuros professores primários não têm educação histórica suficiente, tanto em conteúdos substantivos quanto em competências históricas. Os futuros professores primários revelam nos seus relatos que não contam com os níveis básicos de conhecimentos disciplinares e pedagógicos para ensinar história atendendo aos padrões aceitos pelas investigações de didática das ciências sociais (WINEBURG, 2001; BARTON e LEVSTIK, 2004; VANSLEDRIGHT, 2014). Os motivos desta deficiência são diversos. Por um lado, o programa do grau de Licenciatura em Ensino Primário na Espanha tem falta de conteúdos disciplinares históricos. Por outro lado, a pouca educação histórica aprendida no ensino 
básico. De fato, na Primária e Secundária prevalece um ensino histórico decorrente da memorização de conteúdos factuais ou conceituais. Este fragmento é revelador:

Os muçulmanos assentes desde há anos na península vêm-se invadidos por Jaime I e as suas tropas. Já não me lembro de mais nada porque me ensinaram de memória e naquela altura tive de vomitar isto numa folha. Tudo isto é o que suponho porque realmente não me lembro de o ter dado. (ref. 130 UV)

Neste fragmento, reconhece-se a memorização de conteúdos que não se podem recordar. Esta seria a história escolar aprendida, a lembrança de textos acadêmicos decorrentes do currículo, muitos como narrativa nacional e eurocêntrica. As alterações para um currículo por competências educativas básicas em pouco ou nada teriam modificado este modelo de aprendizagem histórica, uma rotina escolar própria do código disciplinar da história como disciplina e a sua vigência em livros de texto (GÓMEZ, RODRÍGUEZ e MIRALLES, 2015; SÁIZ, 2015) e práticas docentes como exames (FUSTER, 2016; GÓMEZ e MIRALLES, 2015).

Está acreditada a potencialidade educativa de competências de pensamento histórico na Primária. Os trabalhos de Cooper (2014), de Levstik e Barton (2008) ou de VanSledright (2011) mostram esse caminho no qual se prima pelo uso de fontes, métodos de indagação e raciocínio histórico. No entanto, a conceção epistemológica da história como saber fechado e não como uma disciplina intelectual de construção de conhecimentos está muito arraigada em países como Espanha, onde o ensino se baseia no relato linear de fatos do passado selecionados pelo currículo oficial, livros de texto, programação do estabelecimento de ensino e docente. É necessária uma intervenção transversal que aumente a presença da educação histórica (em conteúdos substantivos e em competências históricas, ambos relacionados) nos níveis educativos básicos (Primária e Secundária) e também na formação de futuros docentes. As deficiências documentadas neste estudo na organização de uma narrativa histórica por estudantes do Grau de Ensino Primário confirmam a necessidade de refletir sobre a formação dos professores primários para além dos aspetos pedagógicos e cognitivos genéricos, reforçando a sua educação histórica. 


\section{Referências}

ALFAGEME, Begoña; MIRALLES, Pedro; MONTEAGUDO, José. Diseño y validación de un instrumento sobre evaluación de la geografía y la historia en Educación Secundaria.

Enseñanza de las Ciencias Sociales, v.10, p. 48-60, 2010.

ANGUERA, Maria Teresa et al. Métodos de investigación en psicología. Madrid: Síntesis, 1998.

ASHBY, Rosalyn. Developing a concept of historical evidence: students' ideas about testing singular factual claims. International Journal of Historical Learning, Teaching and Research, v. 4, n. 2, p. 44-55, 2004.

BAGE, Grant. Narrative matters: teaching and learning history through story. New York: Routledge, 1999.

BARCA, Isabel. "Till new facts are discovered': Students'ideas about objectivity in history. In: ASHBY, Rosalyn; GORDON, Peter; LEE, Peter (Orgs.). International review of history education: v.4 - understanding history: Recent research in history education. New York: Routledge, 2005, p. 68-82

BARCA, Isabel; SCHMIDT, Maria Auxiliadora. La consciencia histórica de los jóvenes brasileños y portugueses y su relación con la creación de identidades nacionales. Educatio Siglo XXI, v.31, n. 1, p. 25-45, 2013.

BARCA, Isabel . History and temporal orientation: the views of portuguese-speaking students. In: CHAPMAN, Arthur; WILSCHUT, Arie (Org.), Joined-up history: new directions in history education research. Charlotte, NC: Information Age Publishing, 2015, p. 13-35.

BARTON, Keith. Applied research: educational research as a way of seeing. In: MCCULLY, Alan, MILLS, G.; VAN BOXTEL, Carla (Orgs.). The professional teaching of history: UK and Dutch perspectives. Coleraine, Northern Ireland: History Teacher Education Network, 2012, p. 1-15.

BARTON, Keith; LEVSTIK, Linda. Teaching history for the common good. New Jersey: Lawrence Erlbaum, 2004.

BIGGS, John; TANG, Catherine. Teaching for quality learning at university: what the students does. Berkshire: McGraw-Hill, 2007.

CARRETERO, Mario; BERMÚDEZ, Ángela. Constructing histories. In VALSINER, Jaan (Org.). Oxford handbook of culture and psychology. Oxford: Oxford University Press, 2012, p. 625-646. 
CARRETERO, Mario; VAN ALPHEN, Floor. Do master narratives change among high school students? A Characterization of how national history is represented. Cognition and Instruction, v. 32, n. 3, p. 290-312. 2014.

CLARK, Penney. (Org.). New possibilities for the past: shaping history education in Canada. Vancouver-Toronto: UBC Press, 2011.

COOPER, Hilary. (Org.). Writing History, 7-11: historical writing in different genres. New York: Routledge, 2014.

CORBIN, Juliette; STRAUSS. Anselm. Basics of qualitative research: techniques and procedures for developing grounded theory. Thousand Oaks, CA: Sage, 2008.

DOMÍNGUEZ, Jesús. Pensamiento histórico y evaluación de competencias. Barcelona: Graó, 2015.

FUSTER, Carlos. Pensar históricamente: la evaluación en las PAU de Historia de España. 2016. Tesis doctoral inédita, Valencia: Universidad de Valencia, 2016.

GÓMEZ, Cosme Jesús; MIRALLES, Pedro. ¿Pensar históricamente o memorizar el pasado? La evaluación de los contenidos históricos en la educación obligatoria en España. Revista de Estudios Sociales, v. 52, p. 52-68, 2015.

GÓMEZ, Cosme Jesús; ORTUÑO, Jorge; MOLINA, Sebastián. Aprender a pensar históricamente. Retos para la historia en el siglo XXI. Tempo e Argumento, v.6, n. 11, p. 527, 2014.

GÓMEZ, Cosme Jesús; RODRíGUEZ, Raimundo; MIRALLES, Pedro. La enseñanza de la historia en educación primaria y la construcción de una narrativa nacional: un estudio sobre exámenes y libros de texto en España. Perfiles Educativos, v. XXXVII, n. 150, p. 2038. 2015.

HENRÍQUEZ, Rodrigo; RUÍZ, Marcela. Chilean students learn to think historically: construction of historical causation through the use of evidence in writing. Linguistics and Education, v. 25, p. 145-167, 2014.

KERLINGER, Fred. Investigación del comportamiento: métodos de investigación en ciencias sociales. México: McGraw-Hill, 2002.

KROPMAN, Marc; VAN BOXTEL, Carla; VAN DRIE, Jannet. Small country, great ambitions: Prospective teachers' narratives and knowledge about Dutch history. In: CHAPMAN, Arthur; WILSCHUT, Arie (Orgs.), Joined-up history: new directions in history education research Charlotte. NC: Information Age Publishing, 2015, p. 57-84. 
LEE, Peter. Putting principles intro practice: understanding history. In: DONOVAN, Suzanne; BRANSFORD, John (Orgs.). How students learn: history in the classroom. Whashington: National Academies Press, 2005, p. 31-77.

LÉVESQUE, Stéphane. Thinking historically: educating students for the 21th Century. Toronto: University of Toronto Press, 2008.

LÉVESQUE, Stéphane; CROTEAU, Jean-Philippe; GANI, Raphael. Conscience historiques des jeunes francophones d'Ottawa: sentiment d'appartenance franco-ontarienne et récit du passe. Revue du Nouvel-Ontario, v. 40, p. 177-228, 2015.

LEVSTIK, Linda; BARTON, Keith. Doing history, investigating with children in elementary and middle schools. New York: Routledge, 2008.

LÓPEZ, César. Conceptos y narrativas sobre la nación en estudiantes e historiadores. 2012. Tesis doctoral inédita, Madrid: Universidad Autónoma de Madrid, 2012

LÓPEZ, César; CARRETERO, Mario; RODRÍGUEZ-MONEO, María. Conquest o reconquest? Students' Conceptions of Nation Embedded in a Historical Narrative. Journal of the Learning Sciences, v.24:2, p. 252-285, 2015.

LÓPEZ FACAL, Ramón; SÁIZ, Jorge. Spain: History Education and Nationalism Conflicts. In: GUYVER, Robert (Org.), Teaching History and the Changing Nation State: transnational and intranational perspectives. Londres: Bloomsbury, 2016, p. 201-215

MONTE-SANO, Chauncey. Disciplinary literacy in history: An exploration of the historical nature of adolescents' writing. The Journal of the Learning Sciences, v.19, n. 4, p. 539568, 2010.

PLÁ, Sebastián. Aprender a pensar históricamente: la escritura de la historia en el bachillerato. México: Plaza y Valdés, 2005.

RíOS, Martín. La reconquista: una construcción historiográfica (siglos XVI-XIX). Madrid: Marcial Pons, 2011.

RÜSEN, Jörn. History: narration, interpretation, orientation. Nueva York: Berghahn, 2005.

SÁIZ, Jorge. Educación histórica y narrativa nacional. 2015. Tesis Doctoral inédita, Valencia: Universidad de Valencia, 2015.

SÁIZ, Jorge; LÓPEZ FACAL, Ramón. Competencias y narrativas históricas: el pensamiento histórico de estudiantes y futuros profesores españoles de Educación Secundaria. Revista de Estudios Sociales, v. 52, p. 87-101, 2015. 
SÁIZ, Jorge; LÓPEZ FACAL, Ramón. Narrativas nacionales históricas de estudiantes y profesorado en formación. Revista de Educación, v. 374, p. 118-141, 2016.

SANT, Edda; GONZÁLEZ, Neus; SANTIESTEBAN, Antoni; PAGÈS, Joan; OLLER, Montserrat. How do catalan students narrate the history of Catalonia when they finish Primary Education. McGill Journall of Education, v.50, n. 2/3, p. 341-362, 2015.

SEIXAS, Peter. Assesment of historical thinking. In: CLARK, Penney (Org.). New possibilities for the past: shaping history education in Canada. Vancouver-Toronto: UBC Press, 2011, p. 139-153.

SEIXAS, P.; MORTON, Tom. The big six historical thinking concepts. Nelson: Toronto, 2013

VANSLEDRIGHT, Bruce. Narratives of Nation-State, Historical Knowledge and school history education. Review of Research in Education, v.32, n. 1, p. 109-146, 2008.

VANSLEDRIGHT, Bruce. The challenge of rethinking history education: on practice, theories, and policy. New York: Routledge, 2011.

VANSLEDRIGHT, Bruce. Assessing historical thinking and understandin:. innovation design for new standards. New York: Routledge, 2014

WERTSCH, James. Voices of collective remembering. Cambridge: Cambridge University Press, 2002.

WERTSCH, James. Specific narratives and schematic narrative templates. In: Seixas, P. (Org.). Theorizing historical consciousness. Toronto: University of Toronto, 2004, p. 4962.

WINEBURG, Sam. Historical thinking and other unnaturals acts: charting the future of teaching the past. Philadelphia: Temple University Press, 2001. 
Universidade do Estado de Santa Catarina - UDESC Programa de Pós-Graduação em História - PPGH

Revista Tempo e Argumento Volume 09 - Número 22 - Ano 2017 tempoeargumento@gmail.com 